\title{
Design Electronic Botany Worksheet Generation based on Bloom's Taxonomy for Mobile Learning
}

\author{
Rita Kuo \\ Department of Digital Design \\ Mingdao University \\ ChangHua, Taiwan \\ rita@mdu.edu.tw
}

Keith Ying

Dept. of Information and Computer Engineering

Chung-Yuan Christian University

Chung-Li, Taiwan

keith70167@hotmail.com

\author{
Maiga Chang \\ School of Computing and Information Systems \\ Athabasca University \\ Edmonton, Canada \\ maiga@ms2.hinet.net \\ Jia-Sheng Heh \\ Dept. of Information and Computer Engineering \\ Chung-Yuan Christian University \\ Chung-Li, Taiwan \\ jsheh@ice.cycu.edu.tw
}

\begin{abstract}
Worksheet is a common tool for teachers guiding students learning a subject. This research designs an automatic worksheet generator for constructing a worksheet according to the results of student's online exam. We focus on the worksheet of botany observation and analyze 47 different activities in the worksheet. The relation between the worksheet activity and its cognitive ability can be used to decide what activity should be constructed based on students' test result. A simple example is demonstrated in the end of this paper.
\end{abstract}

Keywords-worksheet; Bloom's taxonomy; automatic generation; mobile learning; knowledge map

\section{INTRODUCTION}

Bloom's Taxonomy is a well known classification for teachers setting learning objectives for students. Bloom categorized the educational objectives into cognitive domain, affective domain, and psychomotor domain [1]. Bloom's Taxonomy has already been used for over 30 years. During the 90s, Anderson and Krathwohl proposed revised cognitive levels called Revised Bloom's Taxonomy (RBT) [3]. Based on the Revised Bloom's Taxonomy, Kuo (2009) uses Knowledge Map [4] as knowledge base to construct an automatic item generator [5]. The teacher can manipulate the Knowledge Map with web-based editor. The automatic item generator then constructs true/false items and multiple choice items according to the knowledge stored in the Knowledge Map and put the generated items in the Answer Sheet database. After students filled the answer sheet, the system generates a cognitive evaluation report for the students and the teacher.

This research designs an automatic worksheet generator to help teachers constructing worksheet based on student's exam results. Section 2 describes how we analyze the traditional paper-based worksheets. The system flow is designed in Section 4 with a simple example demonstration. Section 5 gives a brief summary and describes possible future works

\section{WORKSHEET ANALYSIS}

Worksheet is a sheet of paper containing problems or tasks for students to solve and is a common tool for teachers guiding students learning a subject [6]. To design an electronic worksheet for botany course, this research investigates the worksheets from the Enchanted Learning website [2]. There are 203 activities separated into 23 parts and 9 parts of them describe the worksheet design with 94 different worksheets. We eliminate those spelling, writing, and math relevant worksheets and focus on those field trip and observation relevant worksheets, e.g., "Learn About Plants and Plant Worksheets" and "Drawing Worksheets". The worksheet names have some words which can be used to identify what kind of tasks the students may be asked to do. These words are summarized in the second column of Table 1.

Table 1. Worksheet type analysis

\begin{tabular}{|c|c|c|c|}
\hline Activity Type & Worksheet Name & \# of Worksheet & $\begin{array}{l}\text { sub- } \\
\text { Total }\end{array}$ \\
\hline Classifying & Draw and Compare & 2 & 2 \\
\hline \multirow{6}{*}{ Drawing } & Color & 1 & \multirow{6}{*}{13} \\
\hline & Draw & 1 & \\
\hline & Draw and Compare & 2 & \\
\hline & Follow the Instructions & 2 & \\
\hline & Quilt Coloring Page & 2 & \\
\hline & Symmetrical Picture & 5 & \\
\hline Essay & Printable Read and Answer & 3 & 3 \\
\hline Label Me & Label Me & 6 & 6 \\
\hline Match & Match & 1 & 1 \\
\hline Multiple Choice & Multiple Choice Quiz & 4 & 4 \\
\hline \multirow{2}{*}{ Printout } & Printable Read and Answer & 3 & \multirow{2}{*}{12} \\
\hline & Printout & 9 & \\
\hline Report Chart & Report Chart & 2 & 2 \\
\hline Sequencing Card & Sequencing Card & 2 & 2 \\
\hline Writing & Adjective Describing & 2 & 2 \\
\hline Total & & 47 & 47 \\
\hline
\end{tabular}

According to the instructions described in the website, the worksheets can be classified into 10 different activity types as the first column in Table 1 shows. Some worksheets only cover tasks belonging to single activity type and some 
Table 2. Activity Characteristic and Cognitive Ability Analysis

\begin{tabular}{|c|c|c|c|c|c|c|c|c|c|}
\hline \multirow[b]{2}{*}{ Activity Type } & \multicolumn{4}{|c|}{ Characteristics } & \multicolumn{5}{|c|}{ Cognitive Ability } \\
\hline & $\begin{array}{c}\text { \# of Learning } \\
\text { Object }\end{array}$ & $\begin{array}{c}\text { \# of Learning } \\
\text { Concept }\end{array}$ & $\begin{array}{l}\text { \# of } \\
\text { Attr. }\end{array}$ & $\begin{array}{c}\text { Type of Attr. } \\
\text { Value }\end{array}$ & List & Describe & Summarize & Classify & Order \\
\hline Classifying & $\mathrm{N}$ & 1 & $\mathrm{~N}$ & nominal data & & & & $\mathrm{V}$ & \\
\hline Drawing & 1 & $\mathrm{~N}$ & - & - & $\mathrm{V}$ & & & & \\
\hline Label Me & 1 & $\mathrm{~N}$ & - & - & $\mathrm{V}$ & & & & \\
\hline Match & $\mathrm{N}$ & 1 & 1 & nominal data & & & & $\mathrm{V}$ & \\
\hline Printout & 1 & $\mathrm{~N}$ & - & - & $\mathrm{V}$ & & & & \\
\hline Report Chart & $\mathrm{N}$ & $\mathrm{N}$ & $\mathrm{N}$ & - & & $\mathrm{V}$ & $\mathrm{V}$ & & \\
\hline Sequencing Card & $\mathrm{N}$ & 1 & 1 & ordinal data & & & & & $\mathrm{V}$ \\
\hline Find Plants by Characteristics & $\mathrm{N}$ & 1 & $\mathrm{~N}$ & - & & $\mathrm{V}$ & $\mathrm{V}$ & & \\
\hline Take Picture & 1 & $\mathrm{~N}$ & - & - & $\mathrm{V}$ & & & & \\
\hline
\end{tabular}

$\mathbf{N}$ : the number is greater than 1

- : the characteristic is not important

$\mathbf{V}$ : the activity type has relation to specific cognitive ability

others have tasks in multiple activity types. For example, the worksheet with keyword - "Color" belongs to the "Drawing" activity type, on the other hand, the worksheet with keyword - "Draw and Compare" belongs to both "Classifying" and "Drawing" activity types. The amount of worksheets in the Enchanted Learning website is listed in the third column of Table 1 and we sum up the amount of worksheets for each activity type in the last column.

Considering applying the worksheet into the mobile learning devices and environment, two activity types, "Essay" and "Writing", are excluded. We also eliminate "Multiple Choice" activity type to avoid making students have feelings of they are taking examination while doing the worksheet.

We consider two additional activity types which are suitable for observing plants with mobile devices: "Find Plants by Characteristics" can guide student observing specific characteristics of learning objects; students can use mobile devices to take photos of learning objects for the "Take Picture". The nine worksheet activity types this research considered are listed in the first column in Table 2.

Each activity type has its characteristics, such as the number of learning object involved, the number of learning concept mentioned, the number of learning concept's attribute that students should observe, and the type of the attribute value. Column 2 to column 5 in Table 2 shows the activity characteristics that we analyzed the 47 worksheets.

Take "Classify" activity type as example, the teacher may ask students classify multiple plants into two groups according to the learning concept - "leaf". Students should consider the attributes of leaf while classifying the plants, e.g., leaf shape and margin. The attribute value in this example is nominal data. If the concept's attribute value is ordinal data, like leaf size and growing elevation, the teacher should consider using "Sequencing Card" activity type for construct the worksheet. By doing "Sequencing Card" based worksheet, students are required to arrange the learning objects according to its ordinal attribute values, i.e., the leaf size.

We also analyze the cognitive ability that each activity type based worksheet may cover in training students as Table 2 lists. List is the basic cognitive ability and usually asks students to observe the outlook of one specific learning object which covers multiple learning concepts, such as the leaf and the flower. "Drawing", "Label Me", "Printout", and "Take Picture" are four relevant activity types. Describe and Summarize focus on the attributes of the learning objects in one or multiple learning concepts. Two correspondent activity types are "Report Chart" and "Find Plants by Characteristics".

If the activity asks students think over the meaning of the attribute, students needs higher cognitive abilities, e.g. Classify and Order, to complete the activity. If the attribute value is nominal data, the activity is related to Classify cognitive ability, such as "Classifying" and "Match" activities. On the other hand, if the attribute value is ordinal data, the activity is related to "Order" cognitive ability. This research use "Sequencing Card" as the activity for "Order" cognitive ability.

\section{LEARNING SEQUENCE}

According to the worksheet analysis in section 2, this research designs a system to generate a worksheet according to students' online-test result. We use the automatic item generator mentioned in section 1 as the online-test system. After students having the test, the system retrieves the cognitive diagnostic data from the online test system as the first step is Figure 1. The cognitive diagnostic data will be transformed to the remedial learning data, which records the learning object name, the learning concept, the attribute name, the attribute value, the cognitive level, and the depth of the learning object in Knowledge Map. The third step is using cluster theory to cluster each record into several clusters. In step 4 and step 5 , the system will view the characteristics in each cluster and retrieve suitable activity which follows the analysis in Table 2. At the last two steps, these generated learning activities will be constructed as a worksheet and delivered to students' mobile device.

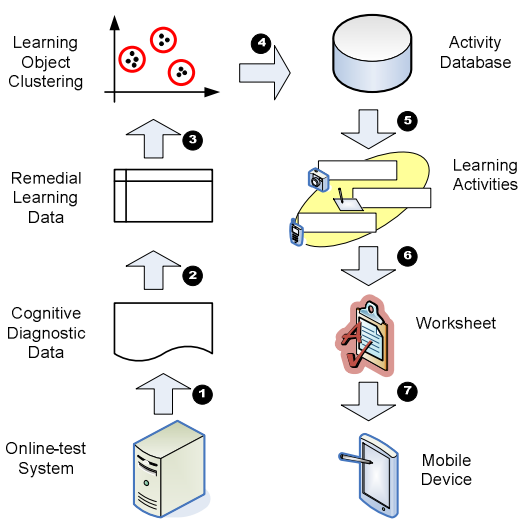

Figure 1. System flow of worksheet generation. 
Here is an example of the automatic worksheet generator. The system retrieves the cognitive diagnostic data from the online-test system mentioned in section 1. The data includes the correct answer, student's answer, the stem of the item, the options in the item, and the cognitive ability of the item.

The system transfers the cognitive diagnostic data to the remedial learning data, which includes:

1. Knowledge depth: the major concepts in the item can be found in the Knowledge Map and the knowledge depth is the depth of the concept node exists in the Knowledge Map. Take Figure 2 for example, the knowledge depth of "Botany" is 0 , and the knowledge depth of "Cerasus serrulata" is 1 .

The knowledge depth of attribute name is related to its belonging concept. For example, the knowledge depth of the attribute name, Arrangement, is 3 because its belonging concept, Leaf, is in knowledge depth 2 . Similarly, the knowledge depth of the attribute value is related to the attribute name it belongs to. For example, the knowledge depth of "Alternate" in Figure 2 is 4, which is one plus the knowledge depth of its belonging attribute name, "Arrangement".

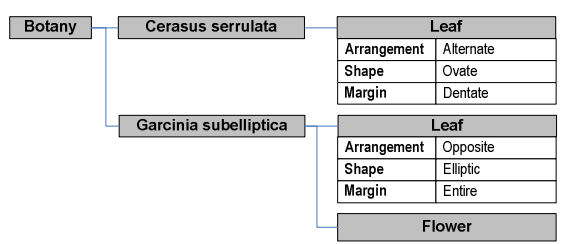

Figure 2. Knowledge Map Example

One record of remedial data has more than two concept nodes of the Knowledge Map. We choose the deepest knowledge depth of concept for presenting this record of the remedial learning data.

2. Cognitive level: each item is related to its cognitive ability. This data can be easily found in the cognitive diagnostic data.

3. Concept name: the concept name is the concept which students should learn of the learning object, such as leaf or flower. The data can be retrieved from the item stem or the options.

4. Attribute name: the attribute name is the attribute of a learning concept, such as the leaf margin or leaf arrangement. The data can also be retrieved from the item stem or the options.

5. Attribute value: attribute value is what kind of attribute the learning object has corresponding to a specific attribute name. The data usually exists in the item options.

In the third step of Figure 1, the system will cluster the records in the Remedial Learning Data into several clusters according to two dimensions, which are cognitive level and knowledge depth. As Figure 3 shows, five clusters are generated by the system. Each cluster has information about number of learning object, number of learning concept, number of attribute, and number of attribute value.
The system will retrieve the suitable learning activity for each cluster according to the analysis in Table 2. Take cluster A for example, the cognitive level of this cluster is 1 , which is corresponding to "List" cognitive ability. "Drawing", "Label Me", "Printout" and "Take Picture" are the available learning activities. The system selects "Drawing" activity by randomly. When all five activities are generated, the system will construct a worksheet and deliver it to students' mobile device.

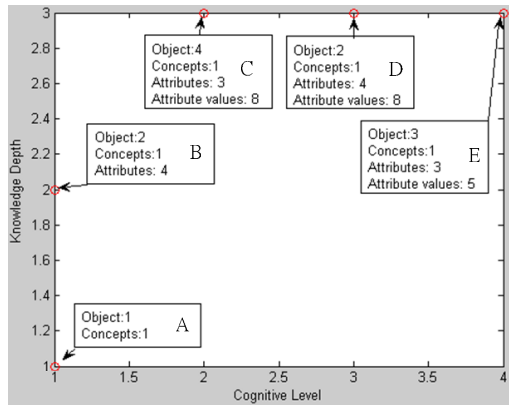

Figure 3. An example of clustering remedial learning data.

\section{CONCLUSION}

This research analyzed the worksheet characteristics and found the relation between worksheet activity and Bloom's Taxonomy. Based on the worksheet analysis, this research also constructed an automatic worksheet generator to generate worksheet according to students' online-test result. An example is demonstrated in the end of this paper.

To know the usability and reliability of the system, we should execute the experiment for gathering teachers' and students' opinion. We should also consider the location factor for deciding the learning object selection in each activity for the future work.

\section{REFERENCES}

[1] B. S. Bloom (Ed.), M. d. Engelhart, E. J. Furst, W. H. Hill, and D. R. Krathwohl, Taxonomy of educational objectives: The classification of educational goals. Handbook 1: Cognitive domain. New York: David McKay, 1956

[2] Enchanted Learning (n.d.). Plants at EnchantedLearning.com. Retrieved http://www.enchantedlearning.com/themes/plants.shtml

[3] D. R. Krathwohl, "A revision of bloom's taxonomy: An overview." Theory into Practice, 41 (4), 2002, pp.212-218.

[4] R. Kuo, M. Chang, D.-X. Dong, K.-Y. Yang, and J.-S. Heh, "Applying Knowledge Map to Intelligent Agents in Problem Solving Systems," In the Proceedings of the World Conference on Educational Multimedia, Hypermedia \& Telecommunications (EDMedia 2002), 24-29 June, 2002, Denver, Colorado, USA, pp.10531054 .

[5] R. Kuo and M. Chang, "Elementary Level Botanical Item Generation," IEEE Learning Technology Newsletter, 11(3), 2009, pp.7-9.

[6] M. F. Mortensen, and K. Smart, "Free-choice worksheets increase students' exposure to curriculum during museum visits," Journal of Research in Science Teaching, 44(9), 2007, pp.1389-1414. 